\title{
RECENT DYNAMICAL FEATURES OF TYNDALL AND GREY GLACIERS, FROM SOUTHERN PATAGONIAN ICEFIELD, BY USING SATELLITE REMOTE SENSING TECHNIQUES
}

\author{
A. C. M. Luzardi ${ }^{1 *}$, C. Cárdenas ${ }^{1}$ \\ ${ }^{1}$ GAIA Antarctica Research Center, University of Magallanes, Manuel Bulnes 01855, Punta Arenas, Chile - (aluzardi, \\ carlos.cardenas)@umag.cl
}

KEY WORDS: Glaciology, Ice dynamics, Offset-tracking, Sentinel, Ice velocity

\begin{abstract}
:
Most glaciers in Patagonia have been rapidly shrinking during the past decades in response to ongoing global warming. To extend techniques to monitor their dynamics is crucial to understand individual glacier response to climate change and its consequences. In that context, our study aims to investigate recent dynamic behaviour of two near-site outlet glaciers placed at the Southern Patagonian Icefield (Tyndall and Grey glaciers) with the usage of simple and cheap remote sensing techniques. Sentinel-1 images were used to estimate surface velocity by using the Offset-tracking algorithm, while Sentinel-2 images were used to estimate area change in the ice front. Moreover, climatic variables (e.g., accumulated precipitation and air temperature) were analysed in order to assess its influence on glacier dynamics. Our results indicates that precipitation rather then temperature changes has been playing a major role in both glaciers retreat. While Tyndall tends to stabilize its retreat, Grey exponentially enhances retreat by its east tongue. Additionally, mean ice speed was of $0.448 \pm 0.242 \mathrm{~m}_{\text {.day }}{ }^{-1}$ for Grey and $0.439 \pm 0.245 \mathrm{~m}$.day ${ }^{-1}$ for Tyndall, which agrees with literature. However, high ice speeds near the ice front indicated by previous work could not be captured here. Our results also suggests that ice flow is a delayed response of precipitation in the accumulation zone, and that may be the cause of decrease in Tyndall's retreat. Overall, Offset-tracking is an useful tool for studying time series of Patagonian glaciers dynamics. It should be used carefully, however, around high dynamical regions such as the glacier terminus.
\end{abstract}

\section{INTRODUCTION}

Most Patagonian glaciers have been rapidly shrinking during the past decades due to recent global warming, which may have implications for sea-level rise (Aniya et al., 1997; Rignot et al., 2003). Moreover, Andes glaciers experienced the largest cumulative mass losses in the world since 1961 (Zemp et al., 2016); from which the Southern Patagonian glaciers presents the most negative mass balance as well as the strongest thinning rates over the entire Andes Cordillera (Dussaillant et al., 2019).

Climate change affects both temperature and precipitation patterns, and thus influences the accumulation and ablation rates of glaciers (Strozzi et al., 2002). Among a huge variety of glaciers typology, outlet as well as calving glaciers have been found to be especially sensitive to climate change (Vieli et al., 2002; Silva et al., 2019).

Water flow through glaciers exerts an important control on ice dynamics, and influences the quantity and quality of water delivered to environments downstream of glacierized basins (Brown, 2002). Glaciers length's variability is a result of change in surface mass balance, its dynamics and the calving rate at the terminus (Vieli et al., 2002; Lutz et al., 2014). Since total mass loss by melting at the calving front is found to be small compared to the mass loss by calving (Vieli et al., 2002), front variability may be a useful proxy for estimating frontal ablation.
Moreover, changes in flow speed may indicate rapid change in glacier dynamics (Ritter et al., 2006). Besides, there is evidence that glaciers flow have been slowing down in response to decades of negative mass balance (Paul et al., 2015). Therefore, to perform a time series analysis of glacier velocity is important to fully understand how glacier dynamics may change over time and how it could related to climate change (Nela et al., 2019).

Despite most Andes glaciers exhibit a trend of retreat, individual responses show spatial and temporal non-uniform patterns, which are determined by combined climatic forces and glacier dynamics. Weidemenn et al. (2018) estimated a negative overall mass balance of $-1.05 \pm 0.18$ mw.e. $\mathrm{a}^{-1}$ and $-2.58 \pm 0.28$ mw.e. $\mathrm{a}^{-1}$ for Grey and Tyndall glaciers, respectively, from April 2000 to march 2016, with a high year to year variability. Therefore, our aim is to estimate recent area change rates as well as surface ice velocity variability for both Tyndall and Grey glaciers from 2015 to 2019 in order to better understand the processes affecting its recent retreat.

\subsection{STUDY AREA}

Both Tyndall and Grey are outlet glaciers with its calving front terminating in progracial lakes. They are located at the Torres del Paine National Park (Chile), and are part of the Southern Patagonian Icefield (SPI), which is the is the second biggest glaciated mass over the Southern Hemisphere (area of 13,218.8 $\mathrm{km}^{2}$; Davies and Glasser, 2012) .

\footnotetext{
* Corresponding author
} 
In 2016, their areas were of $301.4 \mathrm{~km}^{2}$ (Tyndall) and $239 \mathrm{~km}^{2}$ (Grey), which together represents $\sim 4 \%$ of the total SPI area (Meier et al., 2018). As both glaciers are very near from each other, they should present similar climatic patterns (e.g., precipitation, temperature). Hence, difference in their dynamic behaviour should be held mainly by non climatic features.
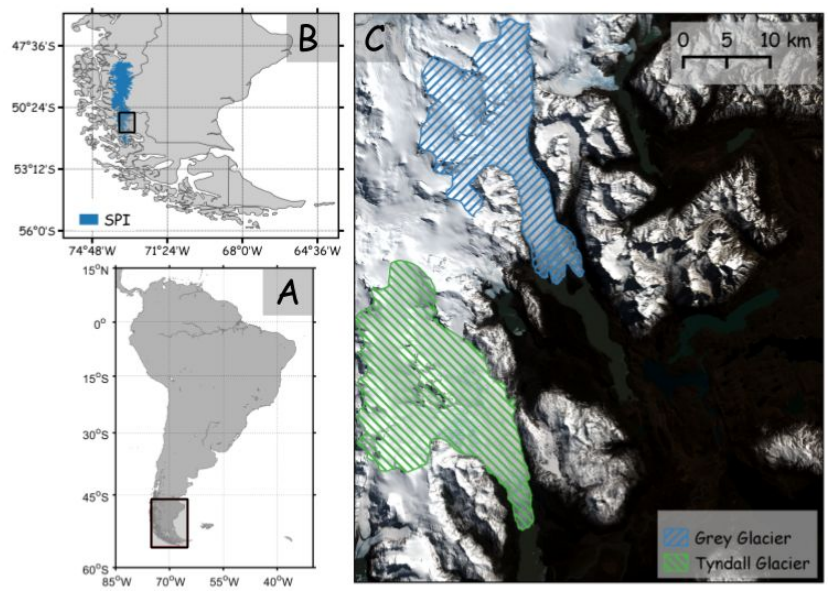

Figure 1. Location of the Southern Patagonian Icefield (SPI), the Tyndall and Grey Glaciers.

\section{DATA}

\subsection{Satellite imagery}

The Copernicus Sentinel-2 mission, created by the European Space Agency (ESA), comprises a constellation of two polar-orbiting satellites placed in the sun-synchronous orbit, phased at $180^{\circ}$ to each other (Sentinel-2A and Sentinel-2B). They carry an optical instrument payload that samples 13 spectral bands: four bands at $10 \mathrm{~m}$, six bands at $20 \mathrm{~m}$ and three bands at $60 \mathrm{~m}$ spatial resolution. The orbital swath width is 290 $\mathrm{km}$, and they are designed to give a high revisit frequency of 5 days at the Equator.

The Sentinel-1 mission is also part of the European Copernicus. It comprises a constellation of two polar-orbiting satellites (Sentinel-1A and Sentinel-1B), operating day and night performing C-band $(5.405 \mathrm{GHz})$ Synthetic Aperture Radar (SAR) imaging, enabling them to acquire imagery regardless of the weather. The images have a square pixels of $10 \times 10$ meters with a nominal resolution of 20x22 meters. Sentinel-1 is able to acquire the following polarisations: $\mathrm{VV}+\mathrm{VH} ; \mathrm{HH}+\mathrm{HV}$; $\mathrm{HH}$ or VV. Level-1 Sentinel images are available in Single Look Complex and Ground Range Detected (GDR). GDR also can be obtained in stripmap, interferometric wide swath, extra wide swath or wave acquisitions, with full, high or medium resolution.

All Sentinel images were freely downloaded from the Copernicus Open Access Hub webpage (https://scihub.copernicus.eu/). Five Sentinel-2 images were acquired from October 2015, January 2016, February 2017, February 2018 and August 2019. These images were Level 1C, which contain radiometric and geometric corrections. In addition, 8 pairs of Level 1 Sentinel-1B images were acquired from the summer and winter of 2017 and 2018. Dates and intervals of SAR image pairs are shown in Table 1. All of them were Interferometric Wide mode at GRD. The images are in right looking mode with descending acquisition geometry and with $\mathrm{VV}+\mathrm{VH}$ polarization.

\begin{tabular}{|c|c|c|}
\hline ID & Date & Interval \\
\hline \multirow{2}{*}{ Image Pair 1 } & $12 / 01 / 2017$ & \multirow{2}{*}{24 days } \\
\cline { 2 - 2 } & $05 / 02 / 2017$ & \\
\hline \multirow{2}{*}{ Image Pair 2 } & $23 / 07 / 2017$ & \multirow{2}{*}{12 days } \\
\cline { 2 - 2 } & $04 / 08 / 2017$ & \\
\hline \multirow{2}{*}{ Image Pair 3 } & $07 / 01 / 2018$ & \multirow{2}{*}{ 12 days } \\
\cline { 2 - 2 } & $19 / 01 / 2018$ & \multirow{2}{*}{24 days } \\
\hline \multirow{2}{*}{ Image Pair 4 } & $11 / 08 / 2018$ & \\
\cline { 2 - 2 } & $04 / 09 / 2018$ & \\
\hline
\end{tabular}

Table 1. Dates and intervals of SAR image pairs.

\subsection{Elevation Data}

The Digital Elevation Model (DEM) was extracted from the ASTER Global DEM Database (https://gdex.cr.usgs.gov/). The ASTER GDEM is distributed as Geographic Tagged Image File Format (GeoTIFF) files with geographic coordinates. Data is posted on a 1 arc second (approximately 30 meters at the equator) grid and referenced to the 1984 World Geodetic System (WGS84)/1996 Earth Gravitational Model geoid.

\subsection{Climatic Variables}

For precipitation analysis, we used the free access monthly mean accumulated precipitation data obtained by the Chilean General Water Direction, which was made available by the Center for Climate and Resilience Research (http://www.cr2.cl/datos-de-precipitacion/). We acquired data from the Torres del Paine station, located at $51.1842^{\circ} \mathrm{S}$ $72.9669^{\circ} \mathrm{W}$, from January 2015 to January 2018 .

For the temperature analysis, we used monthly mean air temperature from 2 meters data from the ERA-Interim reanalysis. We acquired data from the period of January 2015 to December 2019, which was made available from the European Centre for Medium-Range Weather Forecasts at their webpage (https://www.ecmwf.int/). We selected the nearest pixel from the Torres del Paine Station for our analysis, in order to maintain agreement with precipitation data.

\section{METHODS}

\subsection{Area Change trough Ice Front}

Natural color (RGB) images were obtained by the composition of Sentinel-2 bands 4, 3 and 2. Front line positions and area change polygons were created for each image and subsequently pairs, respectively. The QGIS plugin Group Stats (QGIS Development Team 2015) was used to estimate the area of each polygon. By dividing that for the time between each image, it was possible to obtain the rate of area change. 
3.2

\section{Ice Velocity}

Spatial coherence on the glacier surface is affected by weather and flow characteristics, which depends upon the time between acquisitions. In that context, the Offset-tracking algorithm estimates the surface ice velocity through the temporal decorrelation generated by sudden and rapid shifts between neighbour pixels in SAR images (Riveros et al., 2013). Here, Sentinel-1 SAR images were used to obtain the ice surface velocity field through the Offset-Tracking algorithm, which is a part of ESA post-processing software SNAP toolbox. The algorithm uses two stack images (amplitude signal only) previously corregister with a DEM as input and then performs a cross correlation between one master and one slave images over defined ground control points (GCP). Ice velocities were computed based on the offsets estimated and then interpolated over the GCP grid.

The precision of speed values is directly correlated with the coregistration errors, and also depends upon the images spatial resolution (Riveros et al., 2013). This algorithm was found to account for errors up to $1 \mathrm{~m}$ when using ERS and ENVISAT images (Strozzi et al, 2002). In contrast with other precise methods such as GPS or stakes, Offset-tracking has the advantages of being a cheap, fast and straightforward technique for glacier monitoring; hence this technique has a lot of potential. Although it is an useful method for climate studies, SAR Offset-tracking still has been poorly explored around Andes glaciers (Riveros et al., 2013).

\section{RESULTS AND DISCUSSION}

\subsection{Ice Front Positions}

Figures 2 and 3 shows the ice front position of Tyndall and Grey glaciers, respectively, from 2015 to 2019. Tyndall glacier presented interannual retreat in the order of $\sim 200 \mathrm{~m}$, with exception of the 2017-2018 period, when it showed a large advance. Its retreat was clearly more pronounced at its west side, while the east side remained more stable.

With respect to Grey Glacier, its west and central tongues maintained its position almost stable during the entire period. The east tongue, however, presented a major retreat, which became more pronounced at every year, and reached the scale of $\sim 1 \mathrm{~km}$ from 2018 to 2019 .

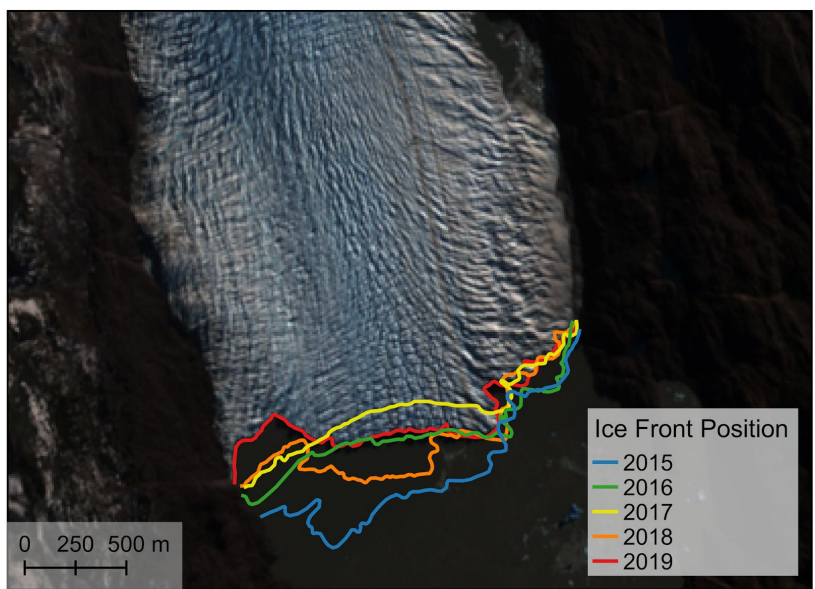

Figure 2. Tyndall Glacier's ice front positions from 2015 to 2019.

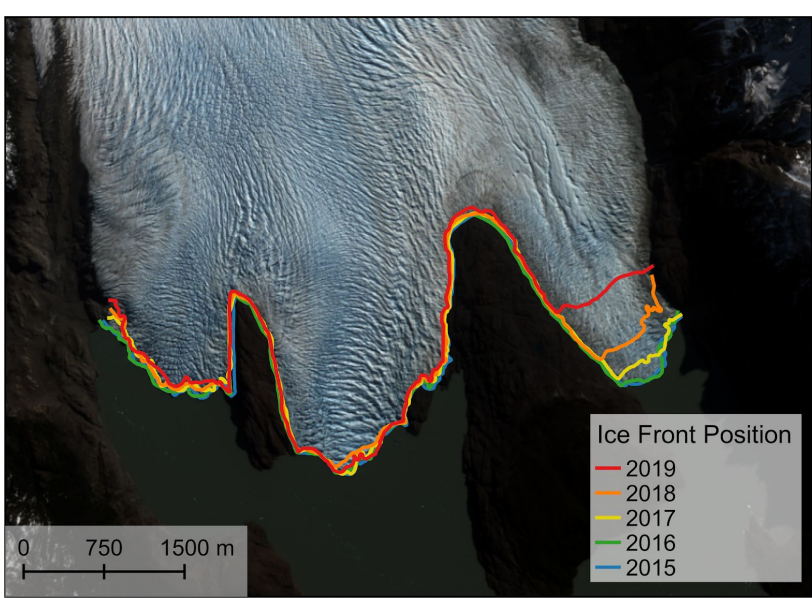

Figure 3. Grey Glacier's ice front positions from 2015 to 2019.

\subsection{Area Change}

Figures 4 and 5 show the rate of area change through the ice front of Tyndall and Grey glaciers, respectively, while Figure 6 shows the contribution of each tongue (e.g., west, central and east tongues) for Grey glacier's area change. Despite their proximity, each glacier presented different patterns of retreat. While Tyndall showed a trend of stabilize its retreat, Grey showed a trend in enhance area loss through ice front, which is mainly caused by its east tongue. Two possible hypothesis for Grey's east tongue fast retreat are a warm water intrusion near the ice front and the presence of a steep slope near glacier terminus, which would enhance the calving rate (Simões et al., 2019). However, the lack of bedrock topography as well as oceanographic data in that site makes it difficult to assess with accuracy which one is more likely.

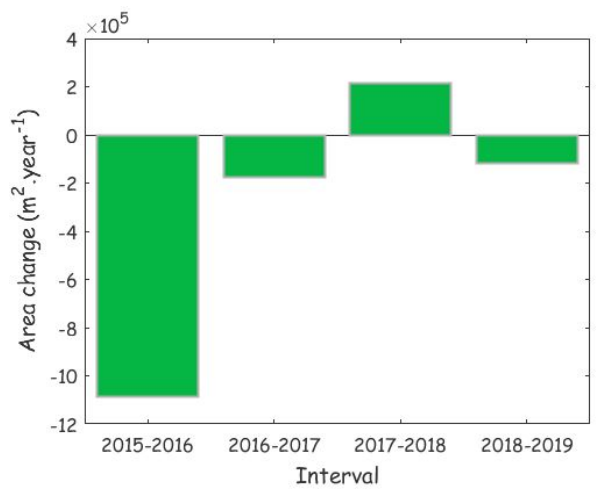

Figure 4. Tyndall glaciers rate of area change in the ice front from 2015 to 2019.

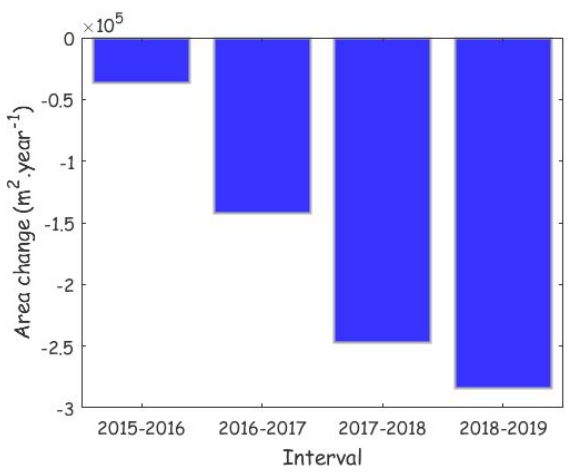


Figure 5. Grey glaciers rate of area change in the ice front from 2015 to 2019.

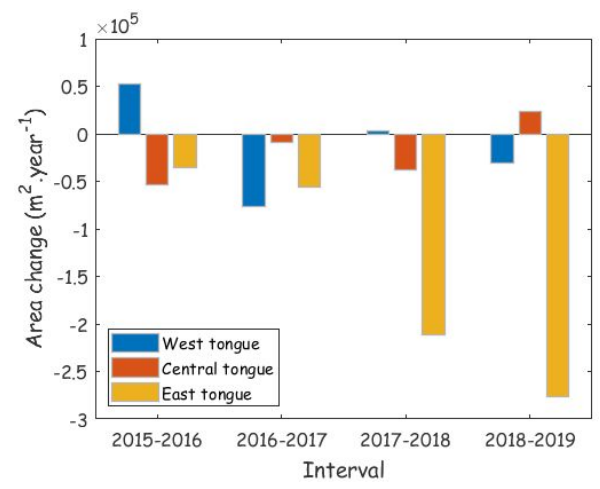

Figure 6. Contribution of each tongue for Grey Glacier's area change in the ice front.

\subsection{Surface Ice Velocity}

Figure 7 shows all ice velocity anomaly fields generated for both Grey and Tyndall glaciers. A high variability of flow speed is shows in the accumulation area, probably due to seasonal changes in precipitation patterns. Moreover, Grey's accumulation zone presented higher speeds during winter season. In Figure 8 there are maps of elevation from the DEM and the mean ice velocity field. General mean velocity was of $0.448 \pm 0.242$ m.day ${ }^{-1}$ for Grey and $0.439 \pm 0.245$ m.day $^{-1}$ for Tyndall. Figures 9 and 10 show profile plots for Tyndall and Grey glaciers, respectively. Longitudinal profiles showed an enhanced flow in high slopes (Figure 9: $a$ and b; Figure 10: a and b), while the cross sections (Figure 9: $\mathrm{c}$ and d; Figure 10: $\mathrm{c}$ and d) showed influence of only slide stress.

Grey's field velocity generally agrees with previous work (Schwalbe et al., 2017), with exception for the glacier terminus. By using terrestrial image sequencing and satellite interferometry, Schwalbe et al. (2017) captured an acceleration on Grey's central tongue terminus reaching up to $\sim 3$ m.day ${ }^{-1}$. Here, we could slightly capture this enhanced speed, however it reached a maximum value of $\sim 0.7$ m.day ${ }^{-1}$. That means the Offset-tracking algorithm may be underestimating puntual high velocity values. Other possible explanation for this discrepancy is that their data is from the summer, while here we have a mean field from 2 years summer and winter.

Figure 11 shows the time series of mean flow speed for each field. Overall, Grey presented a seasonal variability characterized by higher velocity during summer and lower during winter. The increase in velocities during summer may be due to basal sliding generated by melt and/or a delayed response to the accumulation during winter. In contrast, Tyndall presented an interannual variability and absence of seasonality; its velocity enhanced in 2018, which may have caused its decrease in retreat trough front line. Since there was a enhanced precipitation in the winter of 2017, the accelerated flow in 2018 may be a delayed response to the high accumulation in previous year.

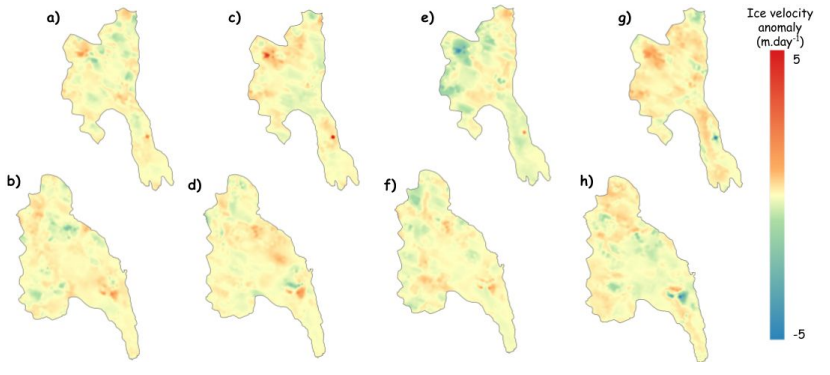

Figure 7. Ice velocity anomaly field for Grey (a, c, e and g) and Tyndall (b, d, f and h), estimated for summer of 2017 ( $a$ and b), winter 2017 (c and d), summer 2018 (e and f) and winter 2018 (g and $\mathrm{h})$.

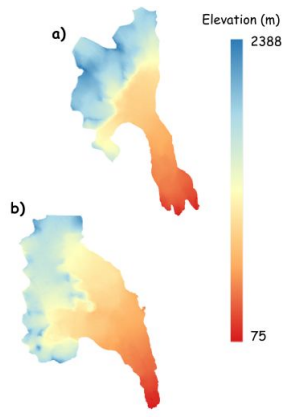

Figure 8. Elevation of Grey (a) and Tyndall (b) glaciers.

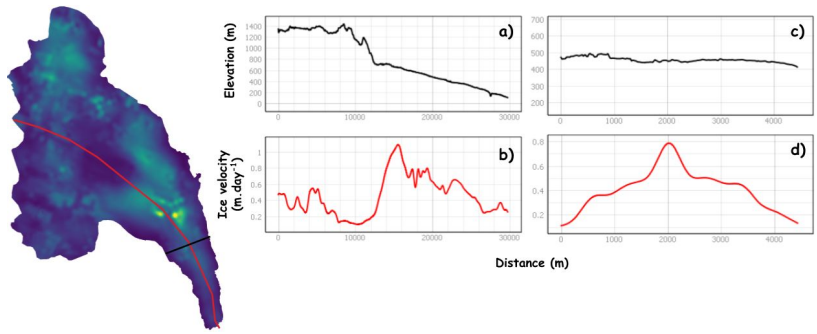

Figure 9. Tyndall Profile plots of (a) elevation at the top-down longitudinal section; (b) ice velocity at the top-down longitudinal section; (c) elevation at the left-right cross section; (d) ice velocity at the left-right cross section.

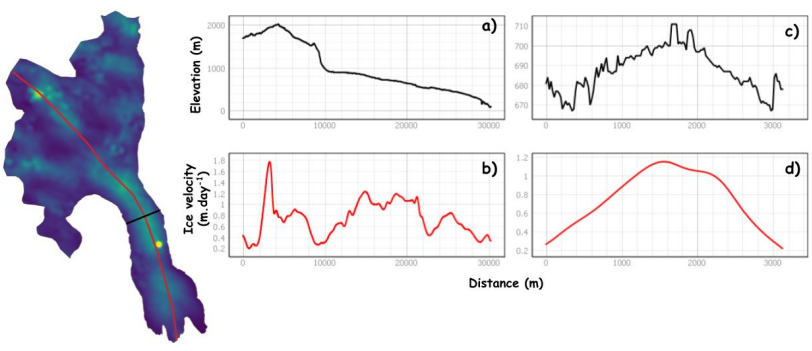

Figure 10. Grey Profile plots of (a) elevation at the top-down longitudinal section; (b) ice velocity at the top-down longitudinal section; (c) elevation at the left-right cross section; (d) ice velocity at the left-right cross section. 


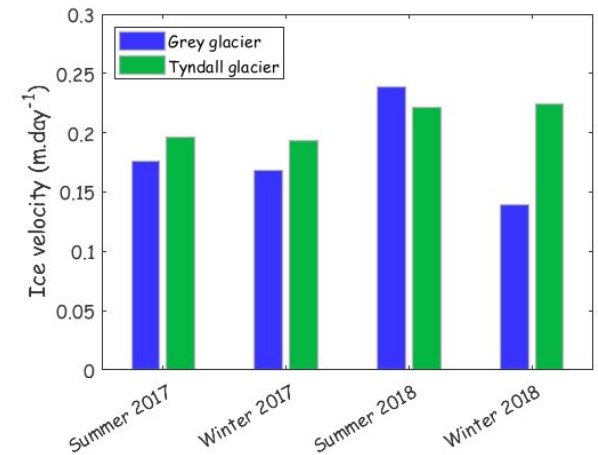

Figure 11. Mean ice velocity for each image pair.

\subsection{Climatic Variables}

Figures 12 shows monthly mean accumulated precipitation time series from January 2014 to November 2017. The accumulated precipitation showed a negative trend of -0.0215 mm.day $^{-1}$, which suggests that the decrease in precipitation has been playing an important role in glaciers retreat during the past recent years.

In Figure 13 are displayed monthly mean temperature time series from January 2015 to August 2019. In contrast with the expected trend of warming of the most part of Andes Cordillera (Carrasco et al., 2002), the ERA-Interim reanalysis showed a very smooth negative trend $\left(-0.000736{ }^{\circ} \mathrm{C}\right)$ in temperature, suggesting steady air temperatures near Torres del Paine station. The stability of air temperatures indicates that this variable has not been playing a major player in both glaciers retreat during recent years.

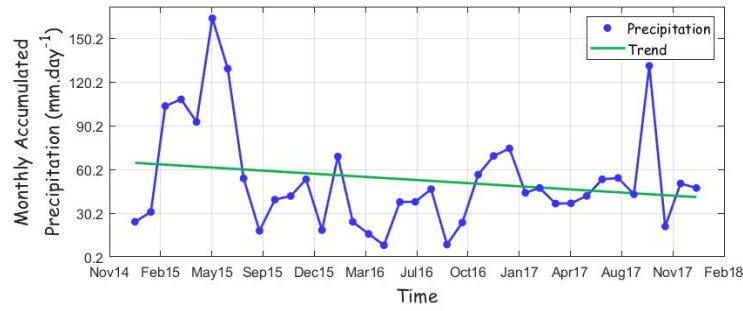

Figure 12. Monthly mean accumulated precipitation (blue line and circles) from January 2014 to November 2017 and its trend line (green).

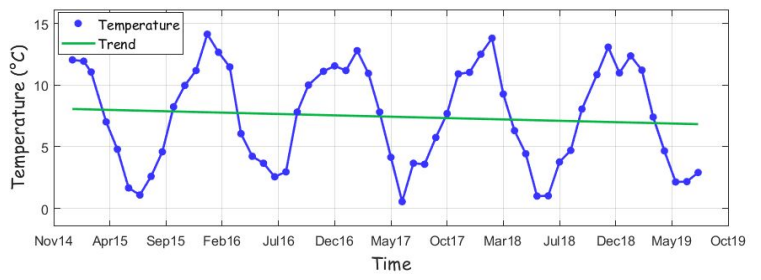

Figure 13. Monthly mean air temperatures from 2 meters (blue line and circles) from January 2015 to August 2019 and its trend line (green).

\section{CONCLUSIONS}

Tyndall and Grey Glaciers are located very near from each other, however, they have been showing different retreat patterns. Both of them have been retreating in response of reducing precipitation, while temperature have been stable in recent years. While Tyndall shows a trend of slowdown in retreat, Grey shows enhanced retreat mainly by its east tongue. Therefore, Grey's east tongue retreat may be driven by a combination of climatic, topographic and oceanographic processes. Ice velocity results suggested an increased flow as a delayed response to high precipitation years in Tyndall glacier, and a seasonal behaviour in Grey glacier characterized by higher speed during summer. Interannual increase in Tyndall's flow speed may have reduced its shrinkage during recent years. In order to better understand these processes, obtaining high resolution oceanographic and subglacial topographic data near glacier terminus are of great importance.

\section{REFERENCES}

Aniya, M., Sato, H., Naruse, R., Skvarca, P., Casassa, G., 1997. Recent glacier variations in the Southern Patagonia Icefield, South America. Arctic and Alpine Research, 29: 1-12.

Brown, G.H., 2002. Glacier meltwater hydrochemistry. Applied Geochemistry, 17:855-883.

Carrasco, J.F., Casassa, G., Rivera, A. 2002. Meteorological and climatological aspects of the Southern Patagonian Icefield. In: Casassa G., Sepúlveda F.V., Sinclair R.M. (eds) The Patagonian Icefields. Series of the Centro de Estudios Científicos. Springer, Boston, MA: 29-41.

Davies, B.J., Glasser, N.F. 2012. Accelerating shrinkage of Patagonian glaciers from the Little Ice Age ( AD 1870) to 2011. Journal of Glaciology. 58: 1063-1084.

Dussaillant, I., Berthier, E., Brun, F., Masiokas, M.M., Hugonnet, R., Favier, V., Rabatel, A., Pitte, P., Ruiz, L. 2019. Two decades of glacier mass loss along the Andes. Nature Geoscience, 12:802-808.

Lutz, A.F., Immerzeel, W.W., Shrestha, A.B., Bierkens, M.F.P. 2014. Consistent increase in high Asian's runoff due to increasing glacier melt and precipitation. Nature Climate Change, 4: 587-592.

Meier, W., Hochreuther, P., Grießinger, J., Braun, M. 2018. An updated multi-temporal glacier inventory for the patagonian andes with changes between the little ice age and 2016 . Frontiers in Earth Science, 6-62. doi: 10.3389/feart.2018.00062.

Nela, B.R., Bandyopadhyay, D., Singh, G., Glazovsky, A.F., Lavrentiev, I.I., Kromova, T.E., Arigony-Neto, J. 2019. Glacier flow dynamics of the Severnaya Zemlya Archipelago in Russian HHigh Arctic using differential SAR interferometry (DInSAR) technique. Water, 11: 2466.

Strozzi, T., Luckman, A., Murray, T., Wegmuller, U., Werner, C. L. 2002. Glacier motion estimation using SAR offset-tracking procedures, IEEE T. Geoscience Remote, 40(11): 2384-2391.

Paul et al., 2015. The glaciers climate change initiative: Methods for creating glacier area, elevation change and velocity products. Remote Sensing of the Environment. 162: 408:426. 
QGIS Development Team (2015) QGIS Geographic Information System. Open Source Geospatial Foundation Project.

Rignot, E., Rivera, A., Casassa, G., 2003. Contribution of the Patagonia Icefields of South America to sea level rise. Science, 302: 434-437.

Ritter, D. F., Kochel, R. C., Miller, J. R. 2006. Process geomorphology, Waveland Press, Long Grove, Ill.

Riveros, N. Euillades, L., Moreiras, S., Balbarani, S. 2013. Offset tracking procedure applied to high resolution SAR data on Viedma Glacier, Patagonian Andes, Argentina. Advances in Geosciences. 35:7-13.

Schwalbe, E.Kröhnert, M., Koschitzki, R., Johnson, E., Cárdenas, C., Maas, H.G. 2017. Determination of spatio-temporal velocity fields at Grey Glacier using terrestrial image sequences and optical satellite imagery. First IEEE International Symposium of Geoscience and Remote Sensing (GRSS-CHILE), Valdivia, 2017, pp. 1-6. doi: 10.1109/GRSS-CHILE.2017.7996022

Silva, A.B., Arigony-Neto, J., Braun, M., Espinoza, J.M.A., Costa, J., Jaña, R. 2019. Spatial and temporal analysis of changes in the glaciers of the Antarctic Peninsula.

Simões, C.L., Rosa, K.K., Simões, J.C., Vieira, R., Costa, R.M., Silva, A.B. 2019. Recent changes in two outlet glaciers in the Antarctic Peninsula using multi-temporal Landsat and Sentinel-1 data. Geocarto International, DOI: 10.1080/10106049.2019.1576776

Vieli, A., Jania, J., Kolondra, L., 2002. The retreat of a tidewater glacier: observations and model calculations on Hansbreen, Spitsbergen. Journal of Glaciology, 48:592-600.

Weidemann, S.S., Sauter, T., Malz, P., Jaña, R, Arigony-Neto, J., Casassa, G., Schneider, C. 2018. Glacier mass changes of lake-terminating Grey and Tyndall glaciers at the Southern Patagonia Icefield derived from geodetic observations and energy and mass balance modelling. Frontiers in Earth Science, 6: $6-81$.

Zemp, M., Huss, M., Thibert, E., Eckert, N., McNabb, R., Huber, J., Barandun, M., Machguth, H., Nussbaumer, S.U., Gärtnet-Roer, I., Thomson, L., Paul, F., Maussion, F., Kutuzov, S., Cogley, J.G. 2019. Global glacier mass changes and their contributions to sea-level rise from 1961 to 2016. Nature, 568: 382-386. 